EESTI NSV TEADUSTE AKADEEMIA TOIMETISED, 23, KOIDE KEEMIA * GEOLOOGIA. 1974, NR. 2

ИЗВЕСТИЯ АКАДЕМИИ НАУК ЭСТОНСКОИ ССР. ТОМ 23 ХИМИЯ * ГЕОЛОГИЯ, 1974, №2 2

\title{
ИЗУЧЕНИЕ ХИМИЧЕСКОГО СОСТАВА СМОЛЫ СКОРОСТНОГО ПОЛУКОКСОВАНИЯ КУКЕРСИТА
}

По скоростному термическому разложению сланца-кукерсита имеется несколько обстоятельных исследований $\left[{ }^{1-7}\right]$, однако или вследствие отсутствия во время проведения этих работ аналитических возможностей для более детального изучения состава смолы, или из-за особенностей методики термолиза сланца, обусловивших неполное разложение керогена, в настоящее время нет достаточной ясности о влиянии скорости нагрева на состав суммарной сланцевой смолы. Вопрос, однако, представляет интерес, так как изменение скорости нагрева является одной из возможностей воздействия на состав продуктов разложения сланца. Кроме того, можно полагать, что при быстром нагреве уменьшится роль вторичных реакций (крекинга первичных низкомолекулярных продуктов разложения и стабилизации более крупных осколков керогена с перераспределением водорода и других склонных к миграции структурных составляющих) и, следовательно, смола будет более явно сохранять черты строения исходного вещества, что может оказаться полезным для определения структуры керогена.

В работе сравниваются две смолы: полученная при стандартной (полукоксование в алюминиевой реторте) скорости нагрева $-5^{\circ} /$ мин и смола скоростного (50\% $/$ мин) полукоксования сланца. Температурный потенциал, требующийся для достижения тақой скорости, еще не слишком высок, а влияние скорости нагрева должно уже четко отразиться на составе смолы. Считается $\left[{ }^{2}\right]$, что нагрев со скоростью более $75^{\circ} /$ мин не может внести существенных изменений в состав продуктов разложения.

\section{Методика}

В опытах исходили из флотационного концентрата кукерсита со следующими показателями: влажность - 5,9\%; зола - 9,6, углекислота карбонатов - 0,9 и условная органическая масса - 89,5\% на сухое вещество. Элементный состав органического вещества: углерод - 78,2, водород - 9,5, гетероатомы - $11,3 \%$.

Навеска концентрата в 6-7 2 помещалась слоем толщиной 3 мм (с целью свести к минимуму роль контактно-пиролитических процессов) между стенкой цилиндрической стеклянной реторты и находящейся внутри ее металлической сеткой. Реторту обогревали электрической трубчатой печью; температуру замеряли в слое сланца, в центре реторты (парогазовая смесь) и в печи. В опытах скоростного полукоксования печь, нагретая до $580^{\circ} \mathrm{C}$, быстро надвигалась на подготовленную реторту, т. е. термическое разложение протекало в условиях изотермического нагрева. Таким путем в области $300-500^{\circ}$ обеспечивалась средняя ско- 
рость подъема температуры $50 \%$ мин (около $70 \%$ мин в начале интервала и $30^{\circ} /$ мин - в конце). При достижении температуры $500-520^{\circ}$ делалась изотермическая выдержка продолжительностью 10 мин, однако смола в этом периоде уже практически не выделялась. Было проведено по 6 опытов стандартного и скоростного полукоксования. Исследовались суммарные образцы смол обеих серий опытов.

Из обезвоженной смолы при 20 мм рт. ст. отгоняли выкипающую до $277^{\circ}\left(420^{\circ}\right.$ при 760 мм рт. ст. [8]) часть, которую после обесфеноливания двукратным избытком $10 \%$-ной гидроокиси натрия разделяли на концентраты групповых компонентов методом тонкослойной хроматографии на силикагеле; элюент - петролейный эфир с пределами кипения 40-70.

Групповые компоненты анализировались в основном газохроматографически на хроматографе «Хром-3» с пламенно-ионизационным детектором в условиях программирования температуры.

\section{Результаты и обсуждение}

Из данных о выходе продуктов полукоксования (табл. 1) следует, что скорость нагревания сланца относительно слабо сказывается на распределении органического вещества между продуктами разложения; это отмечалось и ранее $\left[{ }^{2}\right]$. Из результатов технического и элементного анализа исследуемых смол, а также данных об их групповом составе (табл. 2) вытекает, что смола скоростного швелевания кукерсита отличается от стандартной большей таблица 1 плотностью и более высоким

Выход продуктов полукоксования при стандартном и скоростном режимах

\begin{tabular}{|c|c|c|}
\hline \multirow{2}{*}{ Продукт } & \multicolumn{2}{|c|}{$\begin{array}{l}\text { Выход продукта на оога- } \\
\text { ническое вещество, вес. \% }\end{array}$} \\
\hline & $\begin{array}{c}\text { скоростной } \\
\text { нагрев }\end{array}$ & $\begin{array}{l}\text { стандарт- } \\
\text { ный режим }\end{array}$ \\
\hline $\begin{array}{l}\text { Смола } \\
\text { Вода разложения } \\
\text { Полукокс } \\
\text { Газ и потери }\end{array}$ & $\begin{array}{r}67,3 \\
4,8 \\
14,0 \\
13,9\end{array}$ & $\begin{array}{r}65,1 \\
5,0 \\
16,2 \\
13,7\end{array}$ \\
\hline Сумма & 100,0 & 100,0 \\
\hline
\end{tabular}
содержанием кислородных соединений. Это согласуется с предположением, что в смоле скоростного разложения точнее сохраняются структурные особенности исходного материала. Интересно, что уменьшение количества углеводородов в смоле происходит главным образом за счет алифатических соединений, тогда как количество ароматических углеводородов почти не зависит от скорости подъема температуры.

С ускорением нагрева мало изменяется также состав моно- и полициклических ароматических углеводородов. В смоле скоростного швелевания лишь несколько выше концентрация этилбензола, 1,3,5-триметилбензола, $н$-гексилбензола и индена, ниже - 1,2,4-триметилбензола, тетралина и нафталина. Наиболее заметно зависит от скорости нагрева состав алифатических углеводородов (рис. 1), нейтральных кислородных соединений и фенолов (рис. 2).

В составе алифатических углеводородов смолы скоростного полукоксования, как и в стандартной смоле, преобладают углеводороды нормального строения, но при быстром термолизе отношение $\boldsymbol{H}$-алкены : $\boldsymbol{H}$-алканы в смоле значительно выше (рис. 1). Однако учитывая, что общий выход смолы повышается при скоростном полукоксовании незначительно (табл. 1 , а также $[1,2])$, а суммарное содержание парафино-олефиновых углеводородов в смоле при этом существенно уменьшается (табл. 2), общие ресурсы олефинов в такой смоле даже меньше, чем в смоле стандартного 
Таблица 2

Характеристика смол полукоксования кукерсита

\begin{tabular}{l|c|c}
\hline Показатели & $\begin{array}{c}\text { Смола } \\
\text { скоростного } \\
\text { швелевання }\end{array}$ & $\begin{array}{c}\text { Смола } \\
\text { стандартного } \\
\text { режима }\end{array}$ \\
\hline
\end{tabular}

Суммарная обезвоженная смола:

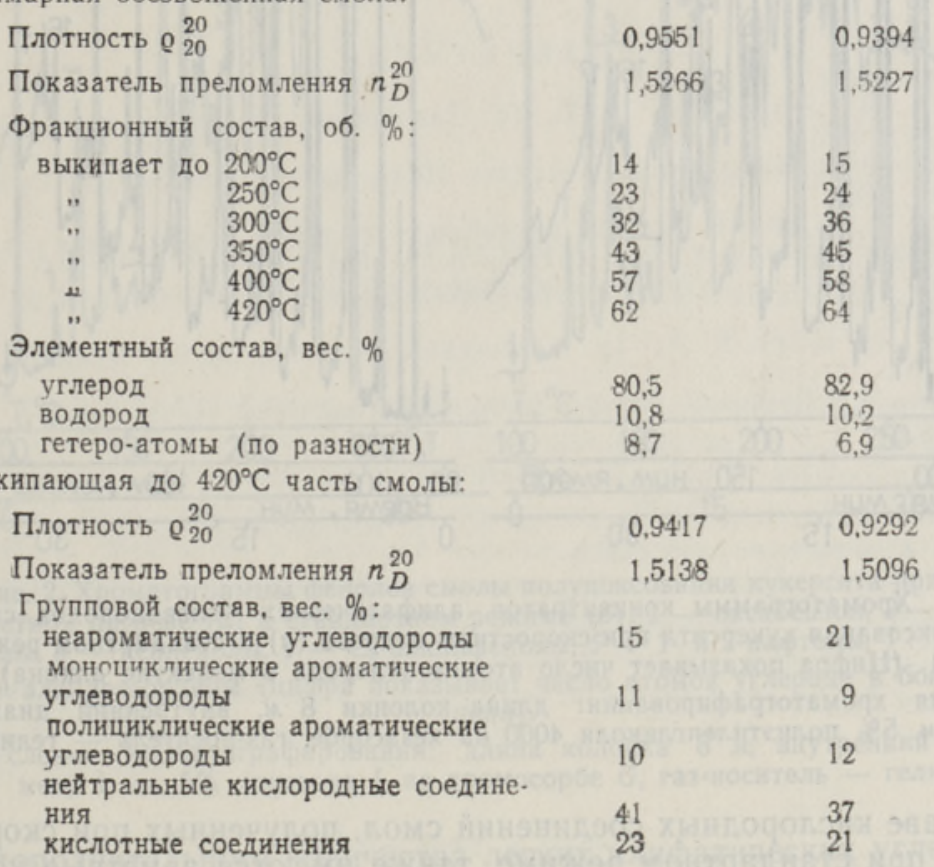

режима (1-олефинов - на $15-20 \%)$. Значит, для скоростного полукоксования характерно не увеличение количества олефинов в смоле, а существенное уменьшение количества $н$-парафинов. Следовательно, в смоле скоростного термолиза должны быть соединения, обеспечивающие образование дополнительного количества алифатических углеводородов при медленном разложении. Ниже будет показано, что такие соединения в смоле действительно имеются.

Другой особенностью парафиновых углеводородов смолы скоростного полукоксования кукерсита является ослабление преобладания соединений с нечетным числом атомов углерода в молекуле. Вероятно, при медленном термическом разложении в процессе термостабилизации крупных осколков распада керогена протекает более полная ароматизация их центральной части, вследствие чего возрастает роль разрыва углеродуглеродной связи в боковых цепях в $\beta$-положении к ароматическому ядру. При быстром же нагреве первичный осколок керогена не успевает ароматизироваться в достаточной мере, чтобы обусловить такую селективность. (Аналогично тому, как высокая избирательность термического распада связей в полистироле исчезает при гидрировании ароматического ядра [9]).

Увеличение отношения парафин : олефин в смоле при медленном термолизе кукерсита также указывает на возросшую роль процесса пере распределения водорода. 

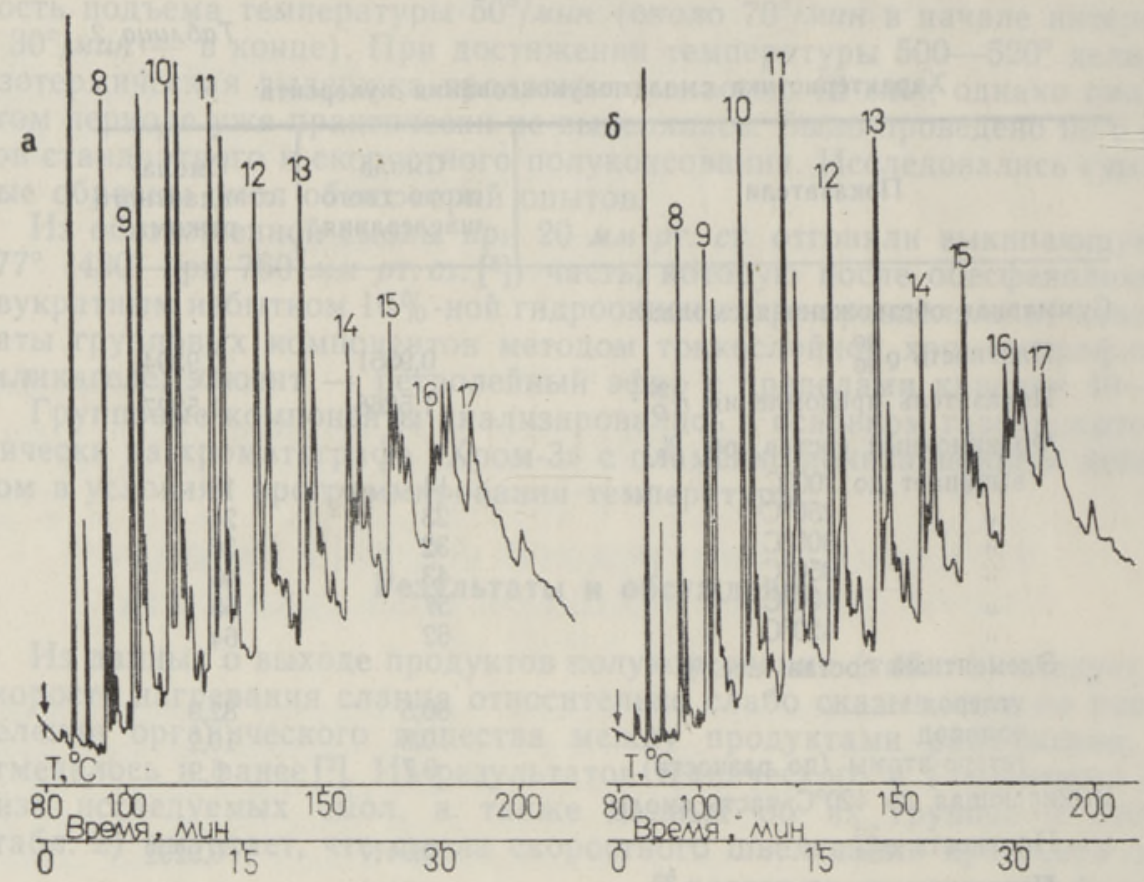

Рис. 1. Хроматограммы концентратов алифатических углеводородов смолы полукоксования кукерсита при скоростном нагреве $(a)$ и стандартном режиме (б). (Цифра показывает число атомов углерода в молекуле алкана).

Условня хроматографирования: длина колонки $8 \mathrm{M}$, внутренний диаметр 3 мм, $5 \%$ полиэтиленгликоля 4000 на хезасорбе, газ-носнтель - гелий.

В составе кислородных соединений смол, полученных при скоростном нагреве и при стандартном режиме, также имеются заметные количественные различия.

Фенолы смолы скоростного термолиза (рис. 2) отличаются намного меньшей концентрацией низкокипящих одноатомных фенолов и значительно более высоким содержанием высококипящих фенолов, особенно 5-н-алкилрезорцинов, боковая цепь которых насчитывает 6-9 атомов углерода. Предполагается, что при обычном полукоксовании часть низших гомологов этого ряда фенолов образуется из высших при термическом расщеплении боковой цепи (отсюда высокая концентрация 5-метилрезорцина, продукта $\beta$-расщепления, в сланцевых двухатомных фенолах). С другой стороны, высококипящие алкилфенолы представляют собой источник образования дополнительного количества алифатических углеводородов при стандартном режиме полукоксования.

На хроматограммах нейтральных кислородных соединений обнаруживается гомологический ряд соединений, которые, как это было показано ранее $\left[{ }^{10}\right]$, являются $\mathrm{H}$-алканонами $\left(\mathrm{C}_{7}-\mathrm{C}_{17}\right)$. При этом в смоле скоростного термолиза, как и в стандартной, по мере удлинения углеродной цепи карбонильная группа смещается к середине цепи. Однако в смоле скоростного полукоксования алифатических кетонов значительно больше, что, по всей видимости, объясняется их разложением при стандартном полукоксовании на алифатические углеводороды и низшие кетоны (в том числе ацетон - основной компонент кетонов сланцевой подсмольной воды). Таким образом, высшие алифатические кетоны или продуцирующие их группировки можно также считать одним из источников образо- 


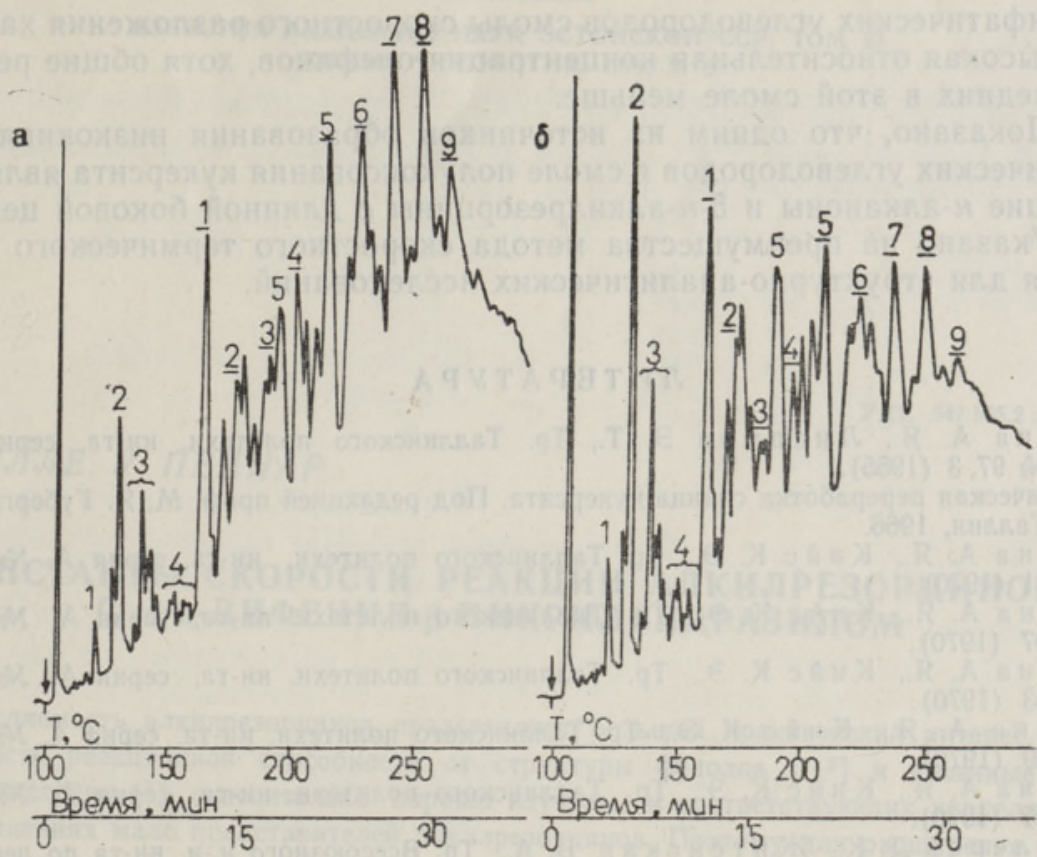

Рис. 2. Хроматограммы фенолов смолы полукоксования кукерсита при скоростном нагреве $(a)$ и стандартном режиме (б). 1 - оксибензол, 2 - крезолы, 3 - ксиленолы, $4-\mathrm{C}_{3}$-алкилфенолы, 5 - 1- и 2-нафтолы, $1 \ldots 9-$ 5-н-алкилрезорцины (цифра показывает число атомов углерода в боковой цепи).

Условия хроматографирования: длина колонка 6 м, внутренний диаметр 4 мм, $5 \%$ апиезона $L$ на хромосорбе $G$, газ-носитель - гелий.

вания дополнительного количества легких алифатических углеводородов при полукоксовании кукерсита. В настоящей работе было также установлено, что выход алифатических углеводородов при стандартном режиме полукоксования по сравнению со скоростным увеличивается в основном именно за счет соединений $\mathrm{C}_{7}-\mathrm{C}_{10}$.

Другой интересной особенностью алифатических кетонов смолы скоростного термолиза кукерсита является явное преобладание соединений с нечетным числом атомов углерода, что, очевидно, связано с природой жирных кислот, участвовавших в образовании керогена кукерсита.

В целом, изменение скорости нагрева кукерсита вносит в состав получаемой смолы лишь количественные изменения; при скоростном нагреве не было обнаружено образования новых групп соединений. Однако при медленном термолизе значительная часть кислородных соединений разлагается с образованием менее связанных со структурой исходного топлива соединений, и поэтому для структурных исследований скоростное термическое разложение обладает определенными преим̆уществами.

\section{Выводы}

1. Установлено, что по сравнению со стандартной смолой смола ско ростного полукоксования кукерсита содержит больше кислородных соединений и меньше алифатических углеводородов. Кислородные соединения отличаются более высоким содержанием высших н-алканонов и 5-н-алкилрезорцинов с длинной (6-9 атомов углерода) боковой цепью. 
Для алифатических углеводородов смолы скоростного разложения характерна высокая относительная концентрация олефинов, хотя общие ресурсы последних в этой смоле меньше.

2. Показано, что одним из источников образования низкокипящих алифатических углеводородов в смоле полукоксования кукерсита являются высшие $\boldsymbol{H}$-алканоны и 5 -н-алкилрезорцины с длинной боковой цепью.

3. Указано на преимущества метода скоростного термического разложения для структурно-аналитических исследований.

\section{Л И Т Е Р А Т Р А}

1. А арна А. Я., Липпм а Э Э. Т., Тр. Таллинского политехн. ин-та, серия А, № 97,3 (1955).

2. Термическая переработка сланца-кукерсита. Под редакцией проф. М. Я. Губергрица. Таллин, 1966.

3. А а рн а А. Я., К ийс К. Э., Тр. Таллинского политехн. ин-та, серия А, № 285 , $31(1970)$

4. А а рна А. Я., К и йс К. Э., Тр. Таллинского политехн. ин-та, серия А, № 285. 37 (1970).

5. А а рна А. Я., К йй К. Э., Тр. Таллинского политехн. ин-та, серия А. № 285. $43(1970)$

6. А а рна А. Я., К й с К. Э., Тр. Таллинского политехн. ин-та, серия А, № 285, 49 (1970)

7. А а рн а А. Я., К ийс К. Э., Тр. Таллинского политехн. ин-та, серия А, № 285, 55 (1970).

8. Коллеров Д. К., Житенская В. А., Тр. Всесоюзного н.-и. ин-та по переработке сланцев, вып. 3, 86 (1955).

9. М а до р ски й С., Термическое разложение органических полимеров, M., 1967.

10. К асберг А. Ф., Клесмен т И. Р., Химия твердого топлива, № 1, 107 (1969).
Ннститут химии
Академии наук Эстонской ССP
Поступила в редакцию 11/XII 1972

\section{K. UROV, I. KLESMENT, O. EISEN \\ KUKERSIIDI KIIRUTMISOLI KEEMILISEST KOOSTISEST}

Kahel erineval kuumutamiskiirusel (5 ja $50 \% \mathrm{~min}$ ) saadud ōlide vördlev analüüs näitas, et kiirutmisõli sisaldab vähem alifaatseid süsivesinikke (peamiselt $n$-alkaanide arvel) ja enam hapnikuühendeid, esmajoones $n$-alkanoone ja pika külgahelaga 5 - $n$-alküülresortsiine. Nimetatud hapnikuühendeist või neid produtseerivatest rühmitustest kerogeenis moodustub standardsetes utmistingimustes täiendav kogus madalal temperatuuril keevaid alifaatseid süsivesinikke.

\section{K. UROV, I. KLESMENT, O. EISEN}

\section{INVESTIGATION OF CHEMICAL COMPOSITION OF THE KUKERSITE-SHALE RAPID LOW-TEMPERATURE CARBONIZATION OIL}

Comparative study of two samples of the oil shale "Kukersite" semicoking oil, obtained at the different heating-up rates $\left(5\right.$ and $\left.50^{\circ} / \mathrm{min}\right)$, has shown that the rapid low-temperature carbonization oil contains a lesser amount of aliphatic hydrocarbons (mainly on account of $n$-alkanes) and is richer in oxygen-compounds, in the first place $n$-alkanones and 5-n-alkylresorcinols with a long side chain. The above-mentioned oxygen-containing compounds or structures they originate from form, under standard semicoking conditions, an additional amount of low-boiling aliphatic hydrocarbons. 